\title{
An Anthropological Study of COVID-19: Effects on Socio-cultural Life of the People
}

\begin{abstract}
Prakash Prasad Sapkota

The disease is such a situation in the body of the people which adversely affect physical, mental, and the social situation remains. This situation appears with an imbalance relation between human's particular biology and his environment. The germ theory of disease trusts scientific theory for the multitude of disease caused by the activities of microorganisms. Coronavirus, too small microorganism cause COVID-19 disease in people. In this paper, an attempt has been made to understand the coronavirus and its effects on the socio-cultural life of the people based on the non-participatory observation and available literature by using descriptive research design. From this study it can be said that, coronavirus caused COVID-19 disease in the respiratory organ of people which is the most sensitive part of the body to alive. Coronavirus has increased fear among the people across the world which directly affects all socio-cultural dimension as educational, economic, inequality and domestic violence, cultural, religious, risk perception, and suicide activities of people. In this situation, it is better to focus on personal safety, complete social responsibility, develop knowledge and skills on both indigenous and modern medicine to cure and protect from such types of pandemic diseases based on their ecological environment.
\end{abstract}

Keywords: COVID-19, culture, impact, society

\section{Introduction}

People always want to do any activities to remain alive as easily as possible within their ecological environment. The lifestyle of people and their activities are directly related to their bodily health. Only healthy people can only actively participate in any daily life activities. Disease is a condition that adversely affects our physical, social, and mental conditions. On one hand, people suffering from the disease are unable to do their daily activities and on the other hand, family members need to spend their time for the treatment of the diseased person. In this situation time, money and knowledge are invested to make the sick person healthy. According to WHO (2011), health is a state of absolute physical, mental, and social well-being and not solely the absence of disease or illness.

There are mainly two types of disease, noncommunicable and communicable disease, among them COVID-19 is a communicable disease. The causative agent of COVID-19 was named as novel coronavirus by WHO on 30 January 2020. In the context of Nepal, the first case of coronavirus was detected on 23 January 2020 in a patient who had returned from Wuhan, China (MoHP,2020). Immediately after the first case was detected, the government of Nepal started working on minimizing the spread and impact of the disease by disseminating information via public broadcasts, including caller tunes on cell phones, training the frontline health care worker, and starting a domestic testing system by establishing testing laboratories. Though, only one positive case of coronavirus had been identified among 212 tested, the infection has now spread rapidly at an alarming rate. It has affected 75 out of 77 districts with 229343 infected persons and 1435 deaths (December 28,2020).

At a cultural level, the ecological equilibrium is established by the accumulation of knowledge concerning the relations between man's particular biology and his environment. It incorporates knowledge of how to secure water, food, and protection from climatic extremes, dangerous animals, and the possible source of disease and illness, poisonous plants, contaminated food, and water by microorganisms are the cultural difference (Katz and Anthony,1974). Theories that deal with health and illness, discuss the ideas people use to explain how to maintain a healthy condition and why they become ill. Ideas about disease/illness causality may incorporate such ideas as a breach of taboo, soul loss, germs, upset in the hot-clod balance of the body, or weakening of the immune system. Anthropologists frequently divide theories of illness into two broad categories: personalistic and naturalistic. COVID-19 is a disease caused by germs (microorganisms), which directly affects the immune system within the respiratory tract and lungs of the people. Naturalistic theories of disease causation tend to view feeling fit and healthy state of harmony between a human being and their environment, when this balance is upset, the disease/illness will result (Encyclopedia,2020). It is found that, the transmission of coronavirus rate is higher in urban areas than rural areas in the context of Nepal as well as around the world, it is because of the imbalance between activities of people and their environment. The modern traditional medicine, familiar with the name of 
biomedicine is ground in the naturalistic deposit of theories concerning the body of the people. These theories are perpetually evolved into the germ theory of disease, which is of relatively recent origin. The germ theory of disease trusts scientific theory for the multitude of disease caused by the activities of microorganisms, coronavirus caused COVID-19 diseases severely at the present. It expresses the view as microorganisms known as pathogens or germs can lead to disease in human beings including other living organisms. These microorganisms which are too small to discern and realize without magnification by using a powerful microscope, intrude on humans, other animals, and other living hosts. In Encyclopedia Britannica, about the Germ theory in the course of medicine, the theory that precise diseases are caused by the annexation of the body of living organisms as people alongside by microorganisms, microorganisms are excessively small but be seen except through a microscope. The disease COVID-19 caused by coronavirus is the smallest microorganism which is only seen by a powerful microscope which can directly affects all activities of the people around the world and appear as fatal.

The occurrence of different pandemic caused by microorganisms frequently in this modern world is one of the most important issues. Are they evolving one after another to adapt to the environment or is it human interest to develop them by applying new technology and knowledge? In the past, people were afraid of tuberculosis, smallpox, plague, AIDS, SARS and now the Covid-19. Most of the diseases are comprehend to the smallest microorganism in the world. About the disease and its dissemination Foucault concerned with:

The processes whereby the human is turned into the subject of scientific investigation and control. Central to this process was the development of modern positivistic medicine as he demonstrated in The Birth of the Clinic. Medical standards of normalcy spread into the human sciences individuating the self, producing subjectivity, and at the same time, providing the basis for social control. The discipline of medicine provided the tools whereby subjectivity could be experienced and enforced. It might transform relations of power/knowledge it could not step outside of them. (White, 2002, p.28).

At present, most of people suspect that powerful countries such as America, China, Russia, Britain, etc. charge each other for the development of new viruses by applying new scientific technology in the process of investigation (WHO,2020). The main aim of the investigation is to develop a microorganism as a powerful weapon that helps to control others as concerned by Foucault. Is modern medicine providing the tools of power relations? is one of the intriguing questions of the world. If the knowledge of science and technology is used to develop new tools to grasp power and control others in the name of medicine, this would be unfortunate for the people.

Today, global societies are running in the capitalistic mode of production. The countries of the world are ranked as core, semi-periphery, and periphery in the sense of economic relationship. The three regions are associated together in the world-system structures and the relationship among them can be described as the assemblage of affluence in the bosom in which wealth is void away from the periphery and the semi-periphery to the core. The outcome of this design is that countries in the core set off richer while the countries in the periphery acquire poor (Burhanuddin, 2015). At present, the developed countries spend money on sophisticated scientific technology to develop vaccine to control COVID-19. However, there seems to be competition in developing vaccine so that they can earn a lot of money out of it. It is clear that, peripheral countries don't have much to expend money and develop new scientific technology. So, to save their people, each peripheral country should depend on developed country which can develop and supply the vaccine. In this way the wealth is revoked away from the periphery and semiperiphery to the core country.

\section{The Corona Virus: Pandemic}

The virus is a microorganism that bridge living and nonliving beings because it shows living character only when it enters into the living organism. So, when it enters into the body it can directly affect the health of people and their activities according to its nature. Due to the thick protein coat around the virus, it can survive in drought conditions and can remain as dust and be crystallized. It is a host as well as an organ specialist, which means that it becomes alive when it gets a suitable host or organ of the living beings. When the virus enters into the body of living beings it can replicate its genome and destroy the cell. When the coronavirus enters into the nose and mouth through droplets and reaches the trachea and cells of the lungs, it starts to replicate its genome and vigorously increase its population and start to destroy lung cells. In this situation, people start to suffer from the fever of more than $100.4^{0}$ Fahrenheit continuously, have a dry cough, feel uneasy in the respiratory tract, and vocal cord, similar to symptoms with pneumonia. Due to increasing severe pneumonia air sacs of the lung filled with fluid, lungs destroy and stop to absorb oxygen and then people die (Haung et al., 2020).

To know why people, die of COVID-19, we should observe the structure of coronavirus. Coronavirus contains a small envelope of glycoprotein at the periphery. Within the envelope membrane glycoprotein, hemagglutininacetylesterase glycoprotein and spike glycoprotein forms a globular network structure. Inside this structure, nucleocapsids phosphoprotein are bound by the ribonucleic acid thread in coiled form. When it enters in the human tracheal cell and reach lung cells, the outer protein's threads attach to the cells and penetrate them. Then RNA replicates vigorously, many viruses mature within the cell, and destroy the cell. They also infect other cells. Due to rapid multiplication and destruction of viruses' fluid gets accumulated in air sacs, thus the lungs become unable to exchange gases and oxygen. Infected people die due to scarcity of oxygen. it becomes unable to exchange the 


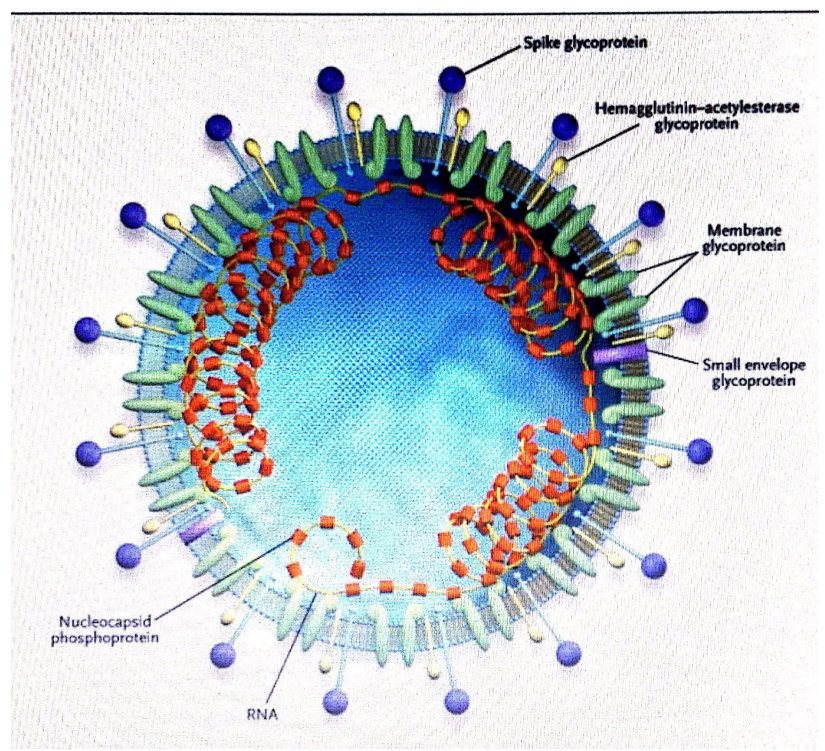

Figure 1: Structure of the Coronavirus Virion. (ref. Holmes, 2020)

gases as well as the absorption of oxygen (Zou et al., 2020).

After the first case of SARS-Co-2 in late 2019 in Wuhan, China (WHO,2020), it has reached to 207 countries globally giving rise to an approximate 12.9 million cases and 569128 deaths. WHO declared that, COVID-19 was pandemic on 30 January 2020. Then researchers around the world started to find out the cause and consequences of the disease and its control measure. Post-traumatic stress disorder (PTSD) is a customary upshot of major disaster. Exceptional epidemic situation has also promoted PTSD in the past. Given the fact that humanity is undergoing pandemic in each decade. The data shows that - in 1720 plague killed one crore 25 lacks, in 1820 - cholera killed 1 lacks, in 1920 Spanish Influenza killed 25.5 thousand people all around the world. At present in 2020, the COVID-19 pandemic is likely to promote PTSD. Moreover, the COVID-19 was renamed severe acute respiratory syndrome coronavirus 2 (SARCCo-2) with a poor understanding of viruses and spreading mechanism, the evocation of SARC is generating great anxiety contributing to promoting PTSD (Haung et al., 2020; Zou et al., 2020; Dutheil et al., 2020)).

At present, coronavirus has become pandemic. People are in fear and are trying to remain safe. It is impossible to figure out who is infected in a large crowd. The situation has worsened even the family members are afraid to touch and meet each other. This situation directly affects the socio-cultural life of the people across the world. People rely on modern as well as traditional medicinal knowledge for the prevention and treatment of COVID-19.

\section{Research and Practice}

At present, COVID-19 has become pandemic and infected people in an alarming rate. In this situation to save people's life and their socio-cultural activities, conducting research and practice and its impacts on human life is one of the most important issues in anthropological concern. It is better to know the developmental history, biology, and impacts of the coronavirus on the human body. In developmental history and biological sense, first month of the year, 2020, Chinese health officials announced the sequencing of the entire genome of an organism, the novel coronavirus that can cause COVID-19, after a few weeks, the first case was discovered. Chinese researchers reported that coronavirus like $\mathrm{H} 5 \mathrm{~N} 1$ and $\mathrm{H} 7 \mathrm{~N} 9$ virus present "cytokine Storm" which is the main factor for disease progression. Therefore, blocking the "Cytokine storm " is a key intervention for the treatment of shock, hypoxemia, and multiple organ failure. The research has shown that an artificial liver support system can remove inflammatory factors and block the "cytokine storm", thus reducing damage to the body caused by an inflammatory response, which is of great value for the treatment of severe and critical patients caused by COVID-19. So it is essential to remove inflammatory materials. Similarly, when plasma is available, it is recommended to conduct a plasma exchange in combination with plasma adsorption or double plasma molecular adsorption, perfusion, and filtration. For this they developed a formula as plasma exchange volume $(\mathrm{L})=$ body mass $\left(\mathrm{kg}^{*}(1 / 13) *(1-H e m a t o c r i d e / 100)\right.$, if the plasma is in short supply, it is recommended to exchange more than $2000 \mathrm{ml}$ of plasma at least. Similarly, researchers of America, Britain, Russia, and Australia are continuously engaged in the research of the coronavirus. Most of the countries, engage their researchers to study the characters of coronavirus, its effects, to develop a vaccine. The competition is going on between different countries to produce an effective vaccine; Russia, and China are first in line and the UK, the USA and Australia are also in the race. The head of the states, are eager to be first in the race to find out vaccine that can lead towards the economic height, make economic supreme in this capitalistic mode of production leading world. It is easy to grasp the power and control others in the name of medicine as expressed by Marx and Foucault.

In general, a total of 384 medicinal plants of 85 different families are being employed for the treatment of respiratory diseases (Shah, et al. 2015). The announced plants were used in 12 contrasting respiratory disorders, treatment of cough (214), cold (57), bronchitis (96), flu, (42), respiratory tract infection (27). (Shah, et al. 2015). In Pakistan to treat different flu people use Bistorta amplexicaulis, Cichorium intybus, Cupressus sempervirens, Juniperus excels, Rubus fruiticousus, Viola biflora, Viola serpens (Younis, 2018).

In the context of Nepal, to save people by the effect of coronavirus, the Government of Nepal developed the 6T formula: travel restriction, - testing, tracing, tracking, treatment, and, together with the lockdown process in highly infected area. The government of Nepal imports different materials masks, ventilators, PPC, sanitizer, drugs, for the prevention, treatment and containment of COVID-19 disease. On the other, most of the rural, as well as urban people has been relying on- home remedies by using different plants as medicine. Gurgo, Abeis 
pindrow, Aakamaro (Achyranthes aspera), Gandaino (Achillea mellefolium), Aesculus indica, wood of Cedrus deodara, etc., which are useful to care about respiratory diseases. People with knowledge use mixture of the root of Katuki and Gandaino, and the mixture of Root of Aasuro, root of Rudilo, Gurgo, and buds of Aamba and turer of satuwa (Paris polyphylla). Some of the other use the mixture of powder of turmeric, jawano and hing with hot water. In non-participatory observation with COVID-19 infected informant Ramjhan Khan of year 65, Baglung municipality-4, says:

When I feel uncomfortable with fever and test less of any food and feel always bitter in my tongue as well as don't panic then I contact with the personnel of COVID-19 disease testing center and they test my swab and informed me as I am infected by coronavirus. I decided to stay in my home quarantine. I spent twenty days in home quarantine. I took only two to three spoonful meal a day but I daily take small piece of satuwa with boiled water. I do not use any other medicine. Now, I am free from the coronavirus disease and spent normal life.

It is already noted that, satuwa has antidote property. Based on the view of the respondent it can be said that satuwa can be used to control the effect of the coronavirus. It must be tested and retested within the laboratory about its efficacy.

In the present situation, most of the countries like Nepal, are unable to produce medicine, goods, financial support for research about the coronavirus and its control measures, and equipment that are necessary due to the economic constraints. All the essential goods as subsidiary medicine, marks, ventilator, PPC, sanitizer, and chemical for decontamination of the infected area. In this context, Nepal and other developing countries lie in the periphery and their economic strength becomes poorer and poorer day by day and move into worse condition due to COVID-19.

\section{Transmission}

COVID-19 a is communicable disease transmitted between the people in a geometric web form ratio. Local person-to-person transmission of the virus is determinable to exuviating on the nasopharyngeal, turbinate, and oropharyngeal surfaces (Zou \& Rothe, 2020), then transmitted primarily via airborne droplets ejected from the nose and mouth (Zou, 2020) with an average incubation period of 5-6 days and ranging up to two weeks. The virus can be conveyed to multiple persons by infected persons. So the transmission of COVID -19 is therefore broadly characterized by inter-population transmission and intra-population contagion as locally driven while inter transmission carried out by the people comes from the outside. Socioeconomic status is known to play a significant role in the transmission of infectious diseases, for example, through intra-population contagion among socioeconomically homogenous subpopulations. The spatial difference in transmission of the coronavirus has no correlation between latitude and altitude in the rate of transmission (Holmes, 2020).

After the first case in Nepal was detected on 23 January 2020, the government of Nepal has been working to reduce the spread and impact of the disease. The initial response was to spread information to aware the people about the coronavirus, train frontline health worker and establish central and local laboratories with constrain resources. As government increased testing facilities within the country after the first local transmission, has seen a speedy infection rate with a total of 229343 COVID-19 cases spread in all seven provinces covering 75 out of 77 districts with 1435 people death (28 December 2020). To prevent the spread of COVID-19, contact tracing and testing high risk population in the early stage of its spread is of utmost importance (Anderson et al., 2020). The government of Nepal from local to central has given their effort to maintain physical distancing between people, use lockdown method according to situation of transmission, increase testing rate for suspected people, use contract tracing method to prevent the transmission, prefer for home isolation and manage quarantine up to local level based on their capacity. Most of the people of rural area used their indigenous knowledge by taking foods producing heat, many different types of herbal medicine like turmeric powder, jwano, jimbu, bhodo, satuwa, gira, lawing, chirato, leaf, and flower of tulsi are used according to their availability to overcome the COVID-19 disease. Highly affected people only visit the hospital. To respond to the crisis caused by the coronavirus pandemic, a coordinated effort across many sectors of society is necessary (MoHP,2020) because the treatment of coronavirus only includes supportive therapies till now.

\section{Socio-Cultural Impact}

People, the socio-cultural living being has had far-reaching consequences beyond the spread of the disease COVID-19 shows political, cultural, and social implications in the life of people of the globe.

\section{a) Political and Economic Impact}

In the political dimension, several provincial-level administrators of the communist party of China were dispersed over their handling of the quarantine endeavor in central China. It reflects a sign of discontent with the political establishment's response to the outbreak in those regions. Due to the fear of coronavirus, immigration in Hong Kong and Taiwan has banned immigration from central China, as hits the One-China policy and its disputed political status (Peter,2020). The European country, Australia is unable to keep a pledge to maintain a fiscal surplus because of the effect of coronavirus. The president of the United States was criticized for his response, misleading and false claim about coronavirus. The Prime minister of the UK was infected with coronavirus. Iran has been heavily affected by the virus and approximately 10 percent of top officials including the vice-president raised questions about the future survival of the region. In the context of Nepal, all three levels of administrators are 
involved in controlling and managing the corona pandemic but people are bringing the issue, ( bhokale marnu bhanda rogale marnu bash) hunger is above disease. This issue is raised because coronavirus made many poor communities in different places of the world face very challenging socio-economic and livelihood consequences. Similarly, 165 county's political personals are affected by this issue and the disease on the other. This situation directly affects sovereignty because of the potential erosion of political and economic sovereignty that may affect some alreadyenfeebled countries like Italy. World Bank and Global Infrastructure Facility (2020) refers to "the pandemic as "the Greater Financial Crisis", that will bring to the surface pent-up financial and dysfunction... national economics will suffer as a result, and their political sovereignty itself may be severely eroded".

This situation reflects COVID-19 had a strong impact on both developed and developing countries like Nepal, leaving the biggest negative effects on production, networks, a significant reduction in agricultural activities, tourism, trade, and industries in the present capitalistic mode of the economy of the world. This condition may impact on world peace as it appears to have worsened conflict dynamics (Katarina, 2020). In the context of Nepal, most of people want increased efforts from government sectors. They criticized both government and opposition leaders about their activities and efforts. COVID-19 leads towards the worse economic condition of the people in Nepal. There are nearly 3.7 million workers earning their livelihoods in sectors deemed most at risk in economic output by the effect of the coronavirus crisis in Nepal (ILO,2020). It further noted as job risk in accommodation and food service $3.1 \%$, transport and storage $10.6 \%$, construction $20.4 \%$, manufacturing $22.4 \%$, wholesale and retail trade $39.3 \%$ and other $4.2 \%$. Three quarters of workers in the tourism sectors are directly affected by no protection and no income. Nepal is the $19^{\text {th }}$ largest receiver of remittance and Nepali migrant workers sent home \$8.1billion in 2018 (Prasian, 2019). A large number of families depend on remittance but the COVID-19 pandemic has directly affected the foreign job and people have returned home after losing their jobs. This data clearly indicates the worsening of the economic condition of Nepal caused by the COVID-19 pandemic. Rural people however continued their agricultural activity to survive.

\section{b) Educational Impact}

Nearly all governments throughout the globe have temporarily closed educational institutions like schools and universities in an attempt to reduce the cases of COVID-19. It directly affected the educational system worldwide. In 191 countries of the world, this affected over 1.6 billion students(UNESCO,2020). The shutdown of educational institutions, impacts not only students, teachers, and families but has far-reaching economic and societal consequences such as student debt, digital learning, food insecurity, and homelessness; additionally, the access to childcare, health care, housing, internet, and disability services. This impact is more critical for disadvantaged children and their families, relating intersperse learning, compromised nutrition, childcare problems, and resultant economic cost to families who could not work. In the context of Nepal, the pandemic has had serious impacts on students learning and well-being, and it can potentially widen the gaps between advantaged and disadvantaged children in their equitable access to quality education (Dawadi, et al., 2020). As the sequel of the lockdowns, schools and universities in Nepal have been temporarily closed for nearly six months. It is estimated that nearly nine million (8796624) students are affected due to closures in response to the pandemic. Out of the numbers, $11 \%$ are pre-primary, $28 \%$ primary, $39 \%$ secondary, and $5 \%$ are in tertiary education (UNESCO,2020) because of the compulsory closure of educational institutions. Though the e-learning system of education is started only $56 \%$ people in Nepal have access to the internet (Dawadi et al., 2020). Pandit (2020) argues that only 13\% of schools might be able to run online classes. On the basis of ICT infrastructure, access of internet, people capacity to manage internet, laptop or cellphone, as well as teacher's capacity and effectiveness of training, urban and rural areas as well as richer and poorer people have two-tier of inequalities in Nepalese citizens.

\section{c) Inequality and Domestic Violence}

COVID-19 leads community people towards inequality. People from poor socioeconomic background, are more likely to contact coronavirus and die from it (Max and Emma,2020). Poorer families are further to be expected likely to live in crowded housing and work in low-skill jobs, such as supermarkets, elder care, labor work, which are deemed essential during the crisis, lack access to health care, lose their jobs, have become unemployed (Derek, 2020). This situation directly demarked the people to haves and haves- not. When the gap between haves and havesnot increases within the community/country, this leads to conflict as the process of production and the reproduction activities as remarked by Marx. As remarked by Marx, the rate of inequality in the economy, education and other socio- cultural activities are rapidly increasing in Nepal. It will take a long time to decrease the gap between different people and communities.

At present, lockdown is the most popular and applied strategy all over the world to manage corona virus infection. But this situation severely increases domestic violence directly or indirectly. Monetary insecurity, stress, and uncertainty have guide to increased belligerence, which is enforced to change behavior at home. This situation with abusers able to control large amounts of their victims in their daily life (Johnson, 2020). Gender-based domestic violence was already a growing problem in Nepal prior to COVID-19. About domestic violence, UNFPA said, 48\% of women in Nepal had experienced violence at some point in their lives, with $27 \%$ of them experience physical violence (KC, 2020). The cases of women's and girls are physically abusing and that has exacerbated are increased as gender-based violence within the quarantine period or physical distancing process in home. On the other 
hand, collective responses about gender base violence have created even more obstacles on the path of gender equality and exacerbated pre-existing inequalities as well as multiple impacts on women's wellbeing, their sexual and reproductive health (UN,2020). COVID-19 pandemic highly increased social norms and gender inequalities, economic and social stress with restricted movement, and social isolation.

\section{d) Cultural Activities}

Culture is such an important domain that holds the identity of the people within their community and acts as an adaptive function within their local environment. It binds all the members within and between the community in an adhesive and cohesive manner. It is the central foci of people which bring solidarity with the development of knowledge on both material and nonmaterial objects and established ideology, rules, norms, values, customs, religion, and belief with long trial and error test method to adapt within their ecological environment. At present, due to COVID-19, all the cultural activities are severely affected and people feel deep piercing all around the world including people of Nepal. About cultural values, the UN (23, April 2020), said:

The pandemic is forcing us to look deep into ourselves. But culture will remain at the top since it helps cities to be more strong in their position of identity. She (Sharif, M.M.) insisted on the need to capitalize on culture with a cross-cutting approach as an essential element for the recovery, considering communities' needs and local demands $\left(6^{\text {th }}\right.$ thematic session $)$.

Similarly, in this panel discussion, the councilor for culture of Mexico City asserted that as urban societies have been framed by the screening of culture, cultural alliance can be the clue, to edifice a new future, beyond immediacy and urgency. The above mention arguments are emerging based on people's deep religious faith in their cultural activities and to face the pandemic and its impact, and reflected on the way forward and highlighted the basic need for culture to be accommodated at the center, case from Lalitpur, Nepal. From this case, it is concluding that we only achieve true humanity as individuals together with others. It is what we do to others, our values, principles, customs in fact the cultural substructure that grant us humanity. At present what we leave for coming generations and requirement to help us configuration the after-effects. These concluding remarks directly reflect the importance of culturally established norms, values, customs, religious beliefs are concretely bound the people of the community and any kind of natural and artificial disaster as COVID-19 pandemic can be controlled with the capitalize on culture with a cross-cutting approach because societies have been shaped by the logic of culture that gives us humanity.

\section{e) Religious Impact}

The COVID-19 pandemic has a severe impact on religious activities in various ways, including the cancellation of the worship service of various faiths. People spend their life inside their homes. They are controlled to observe, celebrate, and participate in their religious work. This situation leads to frustration, less interest in daily activities, and remain far from soul remains in peace. Many temples, churches, mosques people have in practices to offer worship through Livestream amidst the pandemic. Many ritual rites, ceremonies, and festivals are to become pale. An adherent of many religions has gathered together to pray for the end of the coronavirus pandemic, for those pretentious by it, additionally for the God they trust in to give physicians and scientists the intelligence to battle the disease (Arutz, 2020). The belief on religious activities and faith express in the tone of Kapil Bajracharya, the main priest leading rato machhindranath jatra as:

My family has been conducting the ritual for centuries. I feel very sad that in my tenure as not allowed to carry out the chariot procession. As far as I know, it has never been cancelled before. Similarly, 72-years respondent added- I believe that Nepal is a sacred home for gods. If the gods are angry, we will land into more severe problems than coronavirus. I have a serious objection against the Nepali government's control of religions, which bounds on the sinful as far as I am concerned (Dahal, 2020).

The feeling and expression view denote the importance of the religious activities which bind people within the community. It increases emotional unity between the people and decrease the conflict. This has happened due to fear of transmission of COVID-19. This situation not only affects emotional unity but also affects economy, social activity, and cultural norms which are central foci of the community. Though, the main religious-cultural activities are activated by the forceful faith fighting within the community.

\section{f) Psychological Impact}

Psychologically people of all ages are in fear. Every person is afraid of each other and suspects others to be infected. Similarly, due to doubts that pets or other livestock may pass this coronavirus to humans, many people were unwilling to keep their pets fearing transmission (the UK,2020). In this situation, the mental health of people remains an important issue. Most of the psychologists accept that there is going to be an intense feeling of depression after this, especially as we are dealing with the aftereffects of the economic meltdown. People's feelings are exacerbated to the extremes at the moment, especially because of the uncertainty of what is going to happen (Cleary,2020). People worrying about their financial condition was one of the main challenges during the lockdown, then appears the hidden epidemic of gender-based violence.

\section{g) Risk Perception and Suicide}

When the mind of people focuses on the opposite effect on the more immediate threat of the pandemic rather than others, risk perception appears to cross it. The result of the risk may be positive or negative. In the present situation to take risks against pandemic becomes negative and lead 
to death.

Suicide, the unpleasant situation generally occurs because of mental illness, physical/sexual abuse, losses, aggressive behavior, lack of social support/ social isolation, and poor coping skills. WHO reports that out of the way, the huge public mental health smash has been in the form of strain and impatience, and foretell a revolt in depression, suicide, and substance use in the imminent days (Peter, 2020). At present, people of the world including Nepal are suffering from all above mentioned socio-cultural situations. As mentioned by Durkheim's egoistic type of suicide as individual feel isolated from society and does not receive moral guidance needed to operate in their social environment, and also the anomic type of suicide because of regulation of society disrupted (Moore, 2017), this occurs during an economic boom or depression as well as the guidance of norms and values. In this situation he/she feels hopeless and has no control of their lives would be more likely to commit suicide. At present many people around the world including Nepal have reached similar situations and there's an increase in the suicide rate. In Nepal, the rate of suicide has increased by $25 \%$ after the lockdown began (Bhandari, 2020) because of the uncertainty of the economy that has caused fear among the people.

\section{Coping Strategy}

COVID-19 the viral communicable disease appears in the pandemic form and infected 33,104,260 people and death caused by it is 999433 since the contamination started to at the present (27 September 2020). If the present trends of infection continue, it will kill many more people in the world. The symptoms of this disease are different for different people and different places. It depends on the physiology of people and their immune power. There has been no drug development to eradicate the virus. In each epidemic and pandemic, the disease caused by the virus is suppressed by using developed vaccines. In this context, traditional knowledge to use plants as medicine also appears ahead according to their indigenous as well as acquired knowledge by people in different parts of the world. They use different medicinal plants and their parts based on their ecological environment and knowledge. It also shows some positive reflection according to users. In this mysterious situation about the nature of the disease and saving from it, WHO prefers individual health care as in sanitation, and food taking behavior (WHO,2020). It is better to focus on personal safety (as oneself, family, and community), complete social responsibility, and develop skill to adjust within their own local environment. To control and treat this COVID-19 pandemic refer to travel restriction, testing, tracing, tracking, treatment, and together. Most of the researchers in different countries are striving to develop vaccine by following six steps of research- identify and sequence the virus, determine the target, conduct preclinical trials, conduct clinical trials, obtain regulatory approval, and manufacture and distribute (Holmes, 2020; Jagug \& Kwobah, 2020).

\section{Conclusion}

The virus is the smallest microorganism that causes many diseases in living beings including man. Though it is host and organ-specific, it can severely destroy the host with a high rate of multiplication capacity. Most of the diseases caused by the virus are communicable and spread in an epidemic or pandemic form. Coronavirus causes COVID-19 disease which affects the respiratory organ the most sensitive part of the body. Coronavirus has increased fear among the people across the world which has directly affected all dimensions of people's socio-cultural activities. COVID-19 disease directly affects on economy, education, cultural activities, religious activities, faith, and psychology of the people. It enhances the gap between rich and poor people, haves and haves- not, domestic violence, frustration, and suicide rates. It makes weaken the bond between the people within the community. In this situation, it is better to focus on personal safety, complete social responsibility, and develop knowledge and skills both on indigenous and modern medicine to cure and protect from the diseases based on their ecological environment. Diseases like COVID-19 appeared in an alternate time and space and it should not be used as a tool to grasp the power but to save humanity within this globe.

Acknowledgement:

Not applicable

\section{Funding:}

No funding

Ethical approval for the research:

Not applicable. No institutional approval for the research is required.

\section{Conflict of Interest:}

No conflict of interests.

\section{Ethical Conduct of Research:}

I declare that this research has been conducted ethically and also assured of the confidentiality of the participants.

\section{References}

Anderson, R.M., Heesterbeek, H., Klinkenberg, D. \& Hollingsworth, T.D. (2020). How will country-based mitigation measures influence the course of the COVID-19 epidemic. The Lancet, 395(10228), 931934. https://doi.org/10.1016/S0140-6736(20)30567-5

Arutz, S. (2020). Thousands to prey at western wall for end to COVID-19 epidemic. Israel National News. Retrieved from http://www.israelnationalnews.com/ News/News.aspx/ 276027

Bhandari, R. (2020). Have suicides increased during Nepal lockdown? Nepal Times, September 10,2020.

Buheji, M., da Costa Cunha, K., Beak, G., Mavric, B., 
Landro do Carmo de Souza, Y., Souza da Costa Silva, S., Hanfi, M. \& Chetia Yein,T. (2020). The extent of COVID-19 pandemic socio-economic impact on global poverty: A global integrative multidisciplinary review. American Journal of Economics. vol. 10(4), 213-224. https://doi.org/10.5923/j. economics.20201004.02

Burhanuddin, A. (2015). Rethinking world system theory: A historical and conceptual analysis. Journal Wanuam Jurusan Hubunngan International Universitas, Hasanuddin,(1).Retrieved from https://www. researchgate.net/publication/316472894

Cleary, K. (2020). COVID-19: The pandemic's impact on mental health. News and Features. Retrieved from https://www.spotlightnsp.co.za/2020/05/04 covid-19the-pandemics-impact-on-mental-health/

Dahal, P. (2020). Covid: God may punish Nepal for cancelling rites, religious leaders warn. BBC Nepali, Kathmandu. Retrieved from www.bbc.co.uk/news/ world-asia-54375436

Dawadi, S.; Giri, R.A., \& Simkhade, P. (2020). Impact of COVID-19 on the education sector in Nepal: Challenges and coping strategies. Research Gate. Doi 10.31124/advance.12344336v1

Derek, T. (2020). The coronavirus will be a catastrophe for the poor. The Atlantic. Retrieved from amp.theatlantic. com

Encyclopedia Britannica (2020). Germ theory. www. britannica.com

Holmes, K.V. (2020). Perspective SARS- associated coronavirus. The New England Journal of Medicine. Retrieved form www.nejm.org > full $>$ nejmp 030078 (Holmes-2003).

Haung, C., Wang, Y., Li, X., Ren, L., Zhao, J., Hu, Y., Zhang, L., Fan, G., Xu, J., Gu, X., Ceng, Z., Yu, T., Xia, J., Wei, Y., Wu, W., Li, H., Liu, M.,...Coa, B. (2020). Clinical features of patients infected with 2019 novel coronavirua in Wunan, China. The Lancet, 395(10223), 497-506.https://doi.org/10.1016/S01406736(20)30183-5

International Labor Organization [ILO]. (2020). COVID-19 labor market impact in Nepal. Retrieved from ilo.org/Kathmandu/whatwedo/publicatioins/ wcms_745439/lang_en/indes.htm

Johnson, $\bar{K}$. (2020). COVID-19 coronavirus: Domestic violence is the second, silent epidemic amid lockdown. The New Zealand Herald. www.lushumani. org $>$ article $>$ view. ISSN 1170-0777.

Jagug, F. \& Kwobah, E. (2020). Mental health response to the COVID-19 pandemic in kenya: a review. International Journal of Mental Health systems. pp. 14:68,www.ijmhs.biomedcentral.com>artiles

Katz, S.H. \& Anthony, F.C.W. (1974). An anthropological perspective on behavior and disease. AJPH, vol. 64 (11) pp.1060.

Katrina, M. (2020). From bad to worse? The impacts of covid-19 on conflict dynamics. Conflict Series Uropean Union Institute for Security Studies. www. iss.europa.eu

KC, L. (2020). The pandemic will worsen existing gaps in women's education, income, and employment prospects. The Diplomat. Retrieved form www. thedeplomat.com/2020/06/how-covid-19

Max, F. \& Emma, B. (2020). As coronavirus deepens inequality. Inequality worsens its spread. The New York Times. Retrieved from www. nytimes.com > ...> Europe

MoHP. (2020). Government of Nepal: Ministry of health and population (2020). Novel coronavirus (COVID-19) media briefing. Retrieved from https:// covid 19. moph. gov. np/.

Moore, M.D. (2017). Durkheim's types of suicide and social capital: A cross-national comparison of 53 countries. International Social Science Journal (66), 1, Dio 10.11/issij.12111

Peter, V. (2020). Australia walks back surplus promise on deadly virus. Wildfires Bloomberg L.p Retrieved from en.m. wikipedia.org $>$ wiki $>$ Social_...

Pandit, S. (2020 May 7). Sankatma nirantar sikai. Gorkhaparta. Retrieved from https:// gokhapatraonline.com/opinion/challenges-of-virtualclasses/.

Prasain, S. (2019). Nepal is the $19^{\text {th }}$ largest receiver of remittance with $\$ 8.1$ billion. The Kathmandu Post (10 April). https://kathmandupost.com/money/2019/04/10/ nepal -is-19 $9^{\text {th }}$-largest-receiver - of-remittances-

Rothe, C., Schunk, M., Sothmann, P., Bretzel, G., Froeschel, G., Wallrauch, C., Zimmer, T., Thiel, V., Janke, C., Guggemos, W., Seilmaier, M., Drosten, C., Vollmar, P., Zwirglmaier,K., Zange,S., Wolfel,R. \& Hoelscher, M. (2020). Transmission of 2019-nCoV infection from an asymptomatic contact in Germany. New England Journal of Medicine, 382(10), 970-971. https://doi.org/10.1056/NEJMc2001468

Scarpone, C., Brinkmann, S.T., GroBe, T., Sonnenwald, D., Fuchs, M., \& Walker, B.B. (2020). A multimethod approach for county-scale geospatial analysis of emerging infectious diseases: A cross-sectional case study of COVID-19 incidence in Germany. International Journal of Health Geographics-19(1),32. https://doi.org/10.1186/s12942-020-00225-1

Shah, M.G.; Hussian, M. \& Abbasi, A.M. (2015). Medicinal plants used to treat respiratory tract illness in Kaghan valley, Himalayan region - Pakistan. Department of Botany, Hazara University, Pakistan.

Soper, D.E. (1998). Germ theory of disease or what have all the culture gone? Infectious diseases in obstetrics and gynecology. pp. 1-2. Medical University, South Carolina. vol. 6.

UK, (2020). UK coronavirus lockdown the new rules, and what they mean for daily life. Telegraph. Retrieved from www.telegaph.co.uk>polotics 
UN, (2020). The cultural mobilization in the COVID-19 pandemic live learning experience: Beyond the immediate response to the outbreak. Sixth thematic session. CEST. Global Taskforce of Local, Regional Government. UCLG. Retrieved from uclg.org

UNESCO, (2020). COVID-19 educational disruption and response. Retrieved.

White, K. (2002). An introduction to the sociology of health and illness. SAGE Publications, London, New Delhi. pp. 28.

WHO (2020). Novel Coronavirus (2019-nCoV) situation reports. Retrieved from https:// www. who.int/ emergencies/ diseases/novel-coronavirus-2019/ situation-reports.

WHO (2011). 1948 WHO definition of health-WHO/ Europe. Retrieved from www. euro. who. int $>$ pdf-file.

Zou,L., Ruan, F., Huang, M., Liang, L., Hung, H.,Hong, Z., Yu, J., Kang, M., Song, Y., Xia, J., Guo, Q., Song, T., He, J., Yen, H.-L., Peiris, M., \& Wu, J. (2020). SARS-CoV-2 viral load in upper respiratory specimens of infected patients. New England Journal of Medicine, 382(12), 1177-1179. https://doi. org//10.1056/NEJMc 2001737

Prakash Prasad Sapkota, https://orcid.org/0000-00016070-8404 is a Teaching Assistant in Anthropology and he also serves as Science Program Chief in IOST, at Dhawalagiri Multiple campus, Baglung. He is Ph.D. scholar in Anthropology. He also holds M. Sc. in Botany. $\mathrm{He}$ is also an editor at Dhaulagiri Journal of Sociology and Anthropology. He has published research articlesin different journals related to Anthropology and plant science. His research interest includes ethno-ecology, culture-related with plants

Email: sapkotapps117@gmail.com 